\title{
Microfluidic approaches for the analysis of protein-protein interactions in solution
}

\author{
William E. Arter ${ }^{1,2}$ - Aviad Levin ${ }^{1}$ • Georg Krainer ${ }^{1}$ - Tuomas P. J. Knowles ${ }^{1,2}$
}

Received: 8 January 2020 / Accepted: 2 March 2020 / Published online: 8 April 2020

(C) The Author(s) 2020

\begin{abstract}
Exploration and characterisation of the human proteome is a key objective enabling a heightened understanding of biological function, malfunction and pharmaceutical design. Since proteins typically exhibit their behaviour by binding to other proteins, the challenge of probing protein-protein interactions has been the focus of new and improved experimental approaches. Here, we review recently developed microfluidic techniques for the study and quantification of protein-protein interactions. We focus on methodologies that utilise the inherent strength of microfluidics for the control of mass transport on the micron scale, to facilitate surface and membrane-free interrogation and quantification of interacting proteins. Thus, the microfluidic tools described here provide the capability to yield insights on protein-protein interactions under physiological conditions. We first discuss the defining principles of microfluidics, and methods for the analysis of protein-protein interactions that utilise the diffusioncontrolled mixing characteristic of fluids at the microscale. We then describe techniques that employ electrophoretic forces to manipulate and fractionate interacting protein systems for their biophysical characterisation, before discussing strategies that use microdroplet compartmentalisation for the analysis of protein interactions. We conclude by highlighting future directions for the field, such as the integration of microfluidic experiments into high-throughput workflows for the investigation of protein interaction networks.
\end{abstract}

Keywords Microfluidic $\cdot$ Approaches $\cdot$ Protein-protein interactions $\cdot$ Diffusional sizing $\cdot$ Electrophoresis $\cdot$ Droplet

\section{Introduction}

Proteins form the molecular machinery of life and their interactions control virtually all processes in living organisms (Bork et al. 2004). Between 40,000 and 200,000 proteinprotein interactions (PPIs) are believed to exist in the human interactome (Garner and Janda 2011), which are formed by physical contacts between two or more protein molecules. PPIs in both intra- and extra-cellular space are crucial mechanistic features that determine cellular function through DNA replication, transcription, translation and protein folding, as well as activating signalling cascades, controlling enzyme kinetics and facilitating molecular transport. They are

Tuomas P. J. Knowles

tpjk2@cam.ac.uk

1 Department of Chemistry, University of Cambridge, Lensfield Road, Cambridge CB2 1EW, UK

2 Cavendish Laboratory, University of Cambridge, JJ Thomson Avenue, Cambridge CB3 OHE, UK responsible for the regulation of the immune system and essential for the vast number of processes associated with cellsurface interactions and extracellular signalling pathways. Conversely, aberrant protein-protein interactions underlie the pathologies of protein misfolding conditions, such as Alzheimer's and Parkinson's diseases (Dobson 2003; Chiti and Dobson 2017).

Due to their central role in controlling biological function, PPIs are an area of intense interest for the development of pharmaceuticals with which to modulate cellular processes (Bakail and Ochsenbein 2016). Furthermore, efforts to map the protein interactome, the network of PPIs present within cells, aim to provide an improved knowledge of the complex and subtle variety of PPIs for a deeper understanding of the molecular origins of disease (Ngounou Wetie et al. 2013; Ngounou Wetie et al. 2014). To facilitate these approaches, it is important for PPIs to be identified and characterised. Parallelised microarray (Sutandy et al. 2013), yeast twohybrid (Lin and Lai 2017) and affinity-coupled MS (Morris et al. 2014) methodologies can be used to identify PPIs in a high-throughput manner: however, these methods are 
ineffective when quantifying the magnitude of PPIs. This is an important parameter, since the strength of PPIs is related to their biological role. Thus, many techniques have been developed for the quantification of PPIs in terms of the pairwise dissociation constant $\left(K_{\mathrm{d}}\right)$ for each interaction. Such methods include classical techniques such as nuclear magnetic resonance spectroscopy (Liu et al. 2016), isothermal titration calorimetry (Krainer et al. 2012; Velazquez-Campoy et al. 2015), gel electrophoresis (Vergnon and Chu 1999; Wittig and Schägger 2009) and surface-based approaches such as enzyme-linked immunosorbent assay (ELISA) (Wittig and Schägger 2009) and surface-plasmon resonance (SPR). Commonly, such methods operate slowly, making them unsuitable for the study of weak, transient interactions in a highthroughput manner and require large quantities of reagents; surface-immobilisation of PPI binding partners can modify their affinity due to inhibition of binding sites (GoebelStengel et al. 2011). Furthermore, surface-based approaches are often challenged by non-specific binding and the need for suitable antibody reagents (Güven et al. 2014).

These drawbacks present a demand for experimental techniques that directly assess PPIs in free solution, operate rapidly within a short assay timescale and require minimal sample consumption. In this review, we discuss recent advances in microfluidic methodologies that present potential solutions to these challenges, by enabling rapid, native-state analysis of PPIs. These approaches are often amenable to label-free assay readout, and can be used to improve conventional resonance energy transfer (FRET) or fluorescence-correlation spectroscopy (FCS) experiments (Schuler and Hofmann 2013; Krainer et al. 2019). Microfluidics is a rapidly expanding field based upon the reduction of biological assays to the microscale, in order to access the laminar flow conditions that typify fluid behaviour at these lengthscales (Duncombe et al. 2015; Liu and Liu 2016). Moreover, reagent consumption and experimental timescales are much reduced in microfluidic systems, whilst the potential for assay throughput and parallelisation is enhanced, as described previously (Zhang et al. 2016a, b; Convery and Gadegaard 2019). We thus focus on methodologies that utilise the highly predictable nature of molecular transport under laminar conditions as an analytical tool in of itself, within the context of PPI quantification.

\section{Essential principles of microfluidics}

At the microscale, fluid behaviour differs greatly to that observed in bulk solution (Beebe et al. 2002; Squires and Quake 2005). The low ratio of inertial relative to viscous force at small lengthscales results in laminar flow, where fluid mixing occurs purely through diffusion with complete suppression of chaotic turbulence, which is the primary contribution to mixing in macroscale systems. The laminar regime is characterised by the Reynolds number $\operatorname{Re}=\frac{\text { inertial force }}{\text { viscous force }}=\frac{v \rho L}{\eta} \quad$ (where $\rho$ and $\eta$ are the density and dynamic viscosity of the medium, respectively, $v$ is the velocity of the fluid and $L$ is the characteristic length scale of the fluid movement given by the hydraulic diameter $\left(d_{H}\right)$ of the channel. Laminar conditions exist where $\operatorname{Re} \leq 1800$, ensuring predictable flow conditions for microfluidic applications, where values of $R e \ll 1$ are typical.

The Peclét number $\mathrm{Pe}=\frac{L v}{D}$ (describes the relative rates of molecular convection relative to diffusion. Typically, microfluidic experiments retain large values of Pe to prevent complete diffusional mixing over the assay timescale. This facilitates experimental strategies that are not feasible in the bulk phase, and means that microfluidic assays intrinsically operate on fast timescales. In bulk experiments, surfaces and solid matrices are required to retain segregation of assay components, whereas under microfluidic conditions, the slow rate of mixing through diffusion alone means that the use of surfaces is not necessary. Furthermore, the physical dimensions of microfluidic devices and the micron-scale nature of molecular transport allow a broad range of experimental lengthscales ranging from Angstroms, as with the study of small molecules, to micrometres in the investigation and manipulation of cellular analytes. Microfluidic techniques are therefore well suited to the study of PPIs in conditions close to the native state. Typically, this is achieved through quantification or manipulation of changes in the size or charge of proteins and protein complexes as they participate in PPIs, by exploiting the diffusion-controlled mass transport of analytes to facilitate analysis of PPI systems as they undergo rapid, in situ changes in solution conditions, or by micron-scale compartmentalisation of assays for high-throughput study of PPI in small volumes, experimental strategies that are the subject of this review. Due to their modular nature, microfluidic devices can be combined for multi-step processes (Mazutis et al. 2009) or integrated with electronic components (Cheng and $\mathrm{Wu} 2012$ ) and external hardware for mass-spectrometry (Pedde et al. 2017) or synchrotron-enabled spectroscopy (Bortolini et al. 2019), for example.

\section{Exploiting diffusive mass transport for analysis of PPIs}

\section{Diffusion analysis}

As mixing under laminar conditions occurs solely through diffusion (see above), the mixing rate of analytes under microfluidic flow can be analysed to extract the diffusion coefficient $D=\frac{k_{B} T}{6 \pi \eta R_{H}}$ and thus the hydrodynamic radius $\left(R_{H}\right)$ of biomolecules. This property has been utilised in the development of techniques for the microfluidic diffusional sizing 
(MDS) of biomolecules and PPIs. By recording the change in apparent $R_{H}$ that occurs through protein-protein binding, the presence and strength of PPIs can be observed and calculated. A variety of microfluidic device designs, including $\mathrm{T}$ (Kamholz et al. 1999) and H-junction geometries, flowfocussing mixers and capillary-based assay formats such as Taylor dispersion analyses (Chamieh et al. 2017) have been devised to achieve this in practice, yet all essentially function by co-flow of the protein sample through the microfluidic chip alongside a flanking buffer solution. Analysis of the timeevolution of the protein diffusion profile, as it mixes into the co-flow buffer at known fluid linear velocity, thus affords the diffusion coefficient and $R_{H}$.

For sufficiently large differences in $R_{H}$ between PPI binding partners, microfluidic diffusional sizing (MDS) is capable of resolving the sizes and relative concentrations of a range of different protein species (Arosio et al. 2016). This was demonstrated in the observation of the binding interaction between fibrillar alpha-synuclein, an aggregation-prone protein associated with Parkinson's disease, and a fluorophore-labelled antibody, by flowing the protein sample between two streams of flanking buffer solution in a flow-focussing assay format (Fig. 1(a)). Due to the large difference in $R_{H}$ between the sample components, the resultant diffusion profile of the protein mixture could be deconvoluted into the separate contributions from both bound and fibril-associated nanobody, thus illustrating the nanobody-fibril PPI (Zhang et al. 2016a, b). Through titration of one binding partner against the other, MDS allows the relative proportion of bound vs. unbound ligand to be determined, an approach employed recently (Scheidt et al. 2019) to quantify the dissociation coefficient between a molecular chaperone and amyloid-beta fibrils (Fig. 1(b)), protein deposits that are implicated in the pathology of Alzheimer's disease.

MDS quantification of PPIs is particularly facile when binding partners differ greatly in $R_{H}$, enabling accurate deconvolution of their respective diffusion profiles. However, this feature is not a requirement for accurate analysis of PPIs, which is possible even for binding partners of a similar size, i.e. with values of $R_{H}$ within one order of magnitude. In this scenario, the average diffusion profile, comprising the diffusive behaviour of all labelled sample components, can be assessed as a function of protein concentration during titration of one element of a PPI pair against the other. This approach was used, for example, for the quantitative investigation of the oligomerisation of molecular chaperone HSP70 (Wright et al. 2018), where real-time observation of aggregation kinetics revealed the co-operative nature of subunit association. A similar method has been employed for immunoassay of an antigen-antibody interaction in whole blood (Hatch et al. 2001). Furthermore, diffusion-based techniques have been employed for the analysis of protein aggregation in antibody preparations (Hawe et al. 2011) and in the development of a wash-free ELISA immunoassay (Kurmashev et al. 2019). Moreover, the continuous-flow nature of MDS makes it suitable for uninterrupted analysis of PPIs occurring in real time, as demonstrated by continuous observation of insulin aggregation by flow-focussing MDS (Saar et al. 2016).

\section{Label-free analysis of PPIs in microfluidic systems}

In the examples discussed so far, the diffusion of interacting protein species is observed through fluorophore labelling. However, it is well known that fluorophore conjugation can affect the biochemical properties of tagged proteins. Therefore, a number of recent studies have sought to enable label-free MDS, allowing analysis of wild-type protein interactions in the native state. One such approach employs a latent-labelling strategy (Yates et al. 2015), whereby wildtype proteins and interacting protein mixtures undergo sizedependent diffusion in an $\mathrm{H}$-filter device, before in-situ labelling enables quantification of the extent of diffusion and thus the diffusion coefficient (Fig. 1(c)). This method has been used for the observation of a PPI between monomeric alphasynuclein and a nanobody (Yates et al. 2015), in the study of protein-folding equilibria (Zhang et al. 2018) and in quantifying the phospholipid-dependent binding interaction between peptides relevant to the function of ion channel TRPA1 (Macikova et al. 2019).

An alternative approach to label-free analysis of PPIs is the use of intrinsic fluorescence for the observation of molecular mass transport. By illuminating samples with a UV source at wavelengths below $300 \mathrm{~nm}$, fluorescence imaging of unlabelled proteins is possible through autofluorescence of tyrosine, tryptophan and phenylalanine amino acid residues (Lakowicz 2006). This method has been applied to study the self-assembly of oligomeric alpha-B crystallin (Challa et al. 2018) and protein aggregation of lysozyme and silk fibroin (Toprakcioglu et al. 2019). An additional example of labelfree PPI analysis utilised an electrochemical readout, to report a weak binding interaction between free and membranebound protein in a microfluidic diffusion-analysis assay (Tan et al. 2012).

\section{Rapid sample preparation for single-molecule spectroscopy by diffusive mixing}

In addition to methods that quantify the diffusion of protein complexes for PPI analysis, the well-defined nature of diffusional mixing in microfluidics allows rapid sample preparation and the analysis of weak, transient PPIs. Through diffusion-controlled mixing, analyte concentration can be reduced over many orders of magnitude within milliseconds, in a predictable and controlled manner. This principle has been used in combination with single-molecule microscopy to probe weakly interacting, intrinsically disordered proteins 

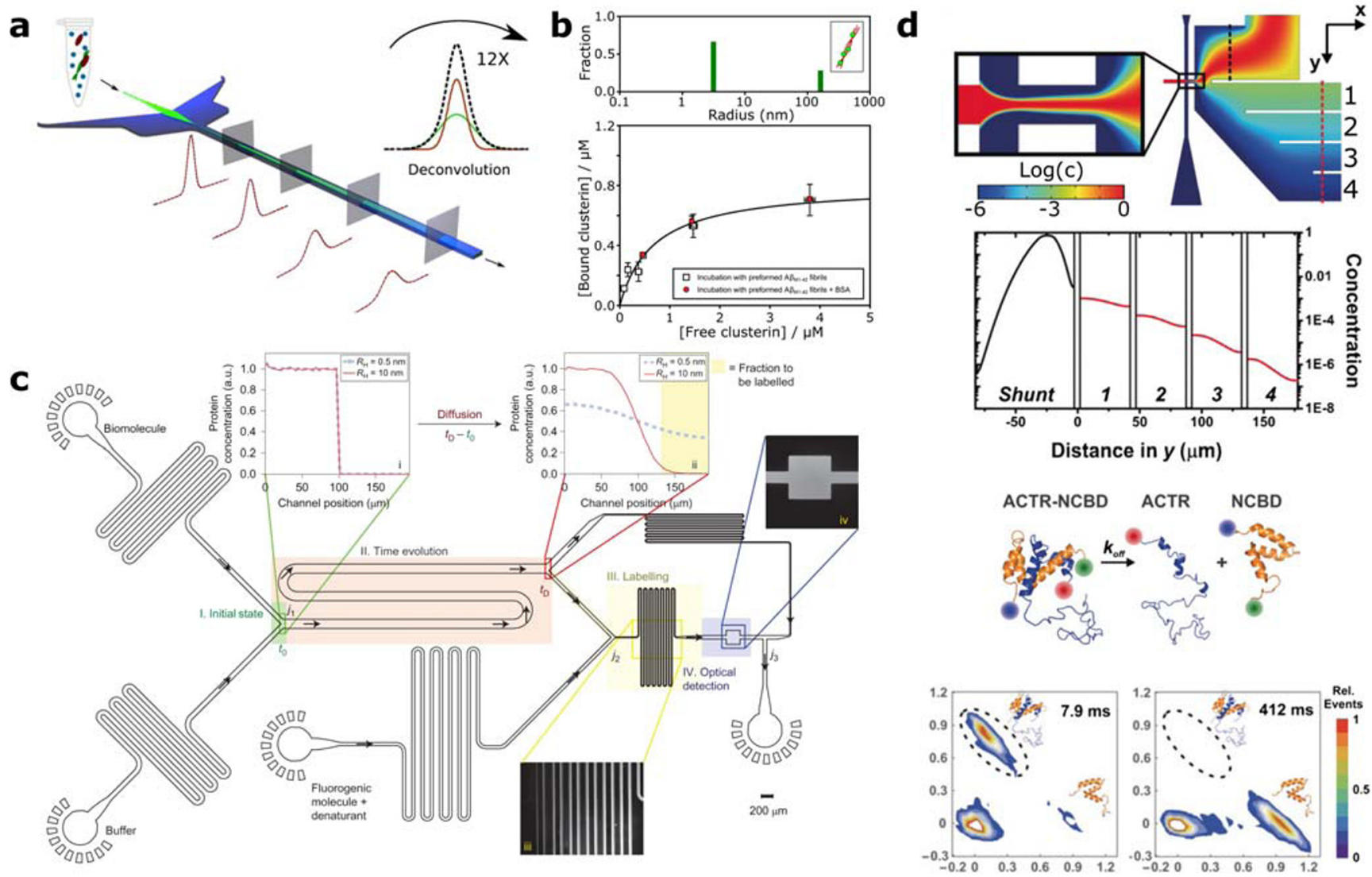

Fig. 1 Microfluidic diffusional mixing for the analysis of PPIs. a Microfluidic diffusional sizing (MDS) by observation of fluorophorelabelled sample flowing between flanking buffer. The temporal change of the Gaussian fluorescence profile is used to determine the diffusion constant (Arosio et al. 2016). b (Upper) MDS data for heterogeneous mixture of clusterin and amyloid-beta fibrils. (Lower) Binding curve for clusterin association to amyloid-beta fibrils generated by MDS (Scheidt et al. 2019). c Device schematic for latent-labelling MDS of proteins and PPI systems. Analytes diffuse by an amount inversely proportional to their hydrodynamic radius in the $\mathrm{H}$-filter region (orange), before labelling

involved in transcriptional regulation (Zijlstra et al. 2017). Complex formation was conducted at $1 \mu \mathrm{M}$ concentration, before diffusional mixing rapidly diluted the sample to concentrations below $100 \mathrm{pM}$ within $3 \mathrm{~ms}$. Through singlemolecule FRET (smFRET) microscopy, the fast dissociation of PPIs could be monitored, allowing quantitative analysis of the dissociation kinetics (Fig. 1(d)). Importantly, diffusioncontrolled mixing enables predictable, rapid sample dilution over $\mu$ s to s timescales, providing high temporal resolution for the quantification of PPI dissociation in weakly bound complexes. Several studies have used this approach for the investigation of weakly bound PPIs within transient (Gambin et al. 2011) and pre-formed oligomers of alpha-synuclein (Horrocks et al. 2012, 2013; Iljina et al. 2016), for example. Conversely, a recent iteration of the microfluidic-dilution technique utilised a passive mixing unit (Lee et al. 2016) for rapid, diffusion-independent mixing, with complete sample dilution within $20 \mathrm{~ms}$. This allowed temporal smFRET analysis of

occur (yellow region) to afford label-free MDS (Yates et al. 2015). d (Upper) Device schematic and computed diffusion profiles for rapid sample dilution for smFRET microscopy. Colour scale depicts relative concentration of the analyte. (Upper middle) Analyte concentration for positions shown in the schematic. (Lower middle) Dissociation reaction between proteins NCBD (donor) and ACTR (acceptor) labelled for FRET microscopy. (Lower) FRET histograms for NCBD-ACTR interaction at $7.9 \mathrm{~ms}$ and $412 \mathrm{~ms}$ after the start of dilution, showing significant complex dissociation within this timescale. Figure taken with permission from Zijlstra et al. 2017

Hsp90 oligomer dissociation under conditions of constant protein concentration (Hellenkamp et al. 2018).

\section{Analysis of PPIs by microchip electrophoresis}

In addition to passive analysis of PPIs through diffusional sizing, molecular transport can be induced directly by the application of an electric field. Electrophoretic methods have long been a staple technique within molecular biology, which typically make use of a gel matrix in order to prevent the chaotic mixing of sample compounds in bulk-scale experiments. Such techniques usually require a significant quantity of sample, and experiments take minutes to hours to run; biomolecular interactions that do not persist over these timescales are therefore challenging to study. In addition, proteins may interact with the matrix and travel through the gel at different rates depending on the solution composition. Gel electrophoresis relies on 
measurements of sample migration relative to a set of reference molecules, and results are therefore not readily comparable between solution conditions. Moreover, resolution is insufficient to distinguish between species of similar MW.

To address these challenges, micro-scale electrophoresis techniques have become ever more prevalent. A principal advantage of microfluidic electrophoresis over traditional gelbased methods is that the slow, diffusion-limited mixing present at the micro-scale precludes the need for a gel separation matrix. Thus, biomolecules and biomolecular mixtures can be analysed and fractionated in their native state, with electrophoresis occurring without mediation by a solid support. Due to the micron-scale dimensions and the requirement to maintain high Pe, as outlined above, experiments can be conducted on sub-second timescales, allowing weak and transient biomolecular interactions to be analysed. Furthermore, the lack of matrix means that the electrophoretic mobility $\mu=\frac{\nu}{E}=\frac{q D}{k_{B} T}=\frac{q}{6 \pi \eta R_{H}}$, where $v$ and $q$ are the electrophoretic drift velocity and net molecular charge, can be determined quantitatively and directly, without recourse to a reference measurement. Moreover, for species of known size, an accurate measure of effective charge can be extracted.

Micro-capillary electrophoresis (MCE) represents the most commonly applied micro-scale electrophoresis technique, whereby the sample mixture is introduced to a microcapillary before an electric field is applied parallel to the capillary axis, causing electrophoretic migration of the sample components through the microchannel (Fig. 2(a)) (Ouimet et al. 2017; Farcaș et al. 2017; Olabi et al. 2018; Voeten et al. 2018). For example, a capillary electrophoresis platform has been used to quantitatively screen modulation of PPIs by small molecules in a drug-discovery context (Fig. 2(b)). The interaction between chaperone HSP70 and co-chaperone BAG3, in the presence and absence of drug candidates, was observed through MCE fractionation of free and complex-bound HSP70, allowing high-throughput identification of hit compounds (Rauch et al. 2013). MCE has recently been employed for the quantification of PPIs between serum albumins and heparinoids (Mozafari et al. 2018), and for the characterisation of the binding interaction of an anti-lyzosyme antibody and dimerisation of HSP70 through a cross-linking approach (Ouimet et al. 2016). MCE has also been used in the analysis of the PPI between actin-scavenger protein Gc-globulin and free actin (Pedersen et al. 2008) (Fig. 2(c)), and the fractionation and quantitation of aggregated and monomeric amyloidbeta (Picou et al. 2012). Further examples include an MCE immunoassay for the quantitation of cancer biomarker alphafetoprotein in human serum (Liu et al. 2017) (Fig. 2(d)), and a competitive immunoassay based upon MCE of anti-thrombin aptamer, for the determination of binding affinities and binding-site identification for distinct anti-thrombin antibodies (Huang et al. 2005).
Furthermore, to MCE, free-flow electrophoresis ( $\mu \mathrm{FFE}$ ) is an additional subset of microfluidic electrophoresis that has been applied to the investigation of PPIs. $\mu$ FFE functions by flowing a sample stream, flanked by an auxiliary buffer, through a microfluidic chip whilst an electric field is applied perpendicular to the direction of flow ((Fig. 2(e))) (Fonslow and Bowser 2005: Turgeon and Bowser 2009; Herling et al. 2013; Saar et al. 2017). The resultant electrophoretic deflection of the sample stream can be analysed to afford the electrophoretic mobility, an approach that has been used for the analysis of protein-ion and protein-ligand interactions ((Fig. 2(f, g)). Due to the free-solution, native-state conditions accessible by this method, quantitative values of the absolute electrophoretic mobility and net molecular charge of analytes can be recorded. This method has been used to quantify the binding constant between modulation and creatine kinase and explore the calcium-dependence of this PPI, for example (Herling et al. 2016) ((Fig. 2(h)). Notably, by monitoring the change in mobility caused by protein-association of one binding partner, this approach can determine PPIs even when fractionation of free and complex-bound proteins is not possible, and due to its gentle nature is suitable for the analysis of weakly interacting PPIs. Furthermore, $\mu F F E$ is capable of analysing interactions such protein-ion binding (Herling et al. 2015) that are inaccessible to size-based methods such as MDS, which are unsuitable in this context due to the negligible increase in hydrodynamic radius that occurs upon association.

As in MCE, sample mixtures may be fractionated during $\mu$ FFE due to differences in mobility between the sample components (Turgeon et al. 2010; Arter et al. 2018); this approach has been used, for example, to observe binding of pro-SPC brichos, a molecular chaperone, to fibrils of aggregated amyloid-beta (Saar et al. 2017) (Fig. 2(i)). In this experiment, fractionation of the fibril-bound and unbound brichos enables in-situ observation and quantification of the extent of chaperonefibril binding. As outlined above, such analyses can be carried out with the use of intrinsic fluorescence microscopy, enabling label-free electrophoretic investigation of PPIs (Wright et al. 2019). Due to its ability to continuously fractionate samples, in contrast to sequential fractionation in $\mathrm{MCE}, \mu \mathrm{FFE}$ is particularly well-suited to preparative applications followed by down-stream analysis of PPIs (Justesen et al. 2013; Eichacker et al. 2014; Wildgruber et al. 2014). Furthermore, $\mu \mathrm{FFE}$ and MCE has shown promise as a facile method for in-line MS analysis of heterogeneous protein mixtures (Figeys and Aebersold 1998; Song et al. 2010; Park et al. 2015).

\section{Analysis of PPIs following microdroplet compartmentalisation}

In addition to the aqueous-phase microfluidic approaches described above, bi-phasic droplet microfluidics represent 
a

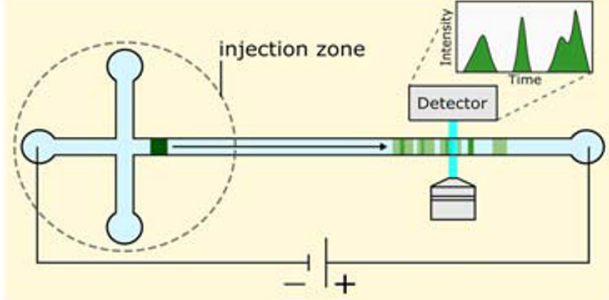

b
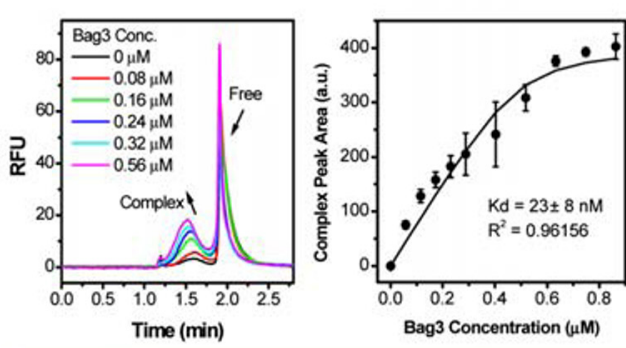

e

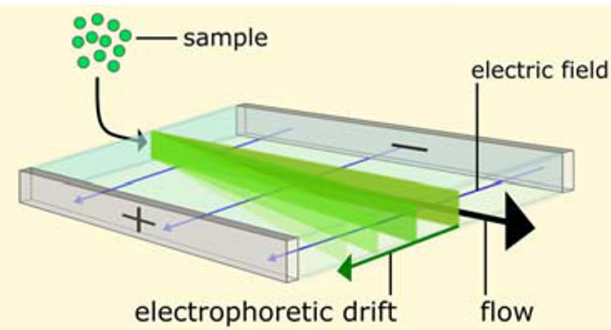

$\mathbf{g}$
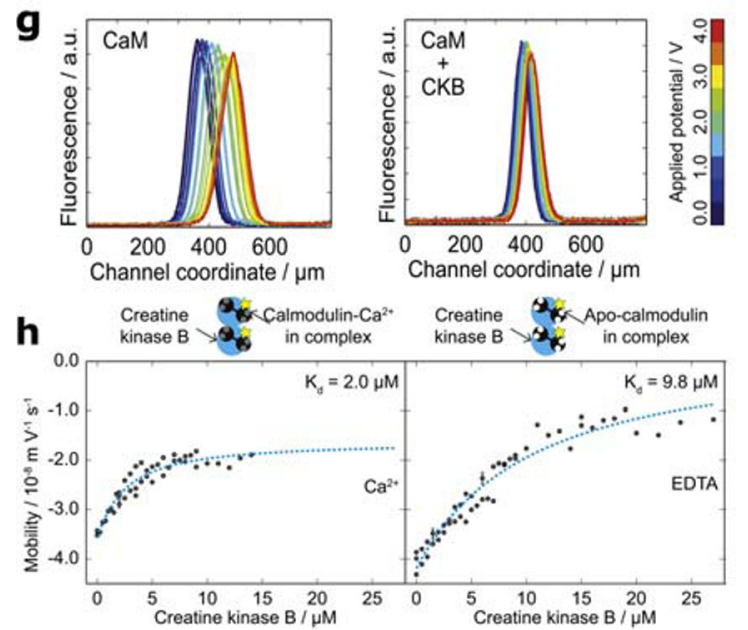

i
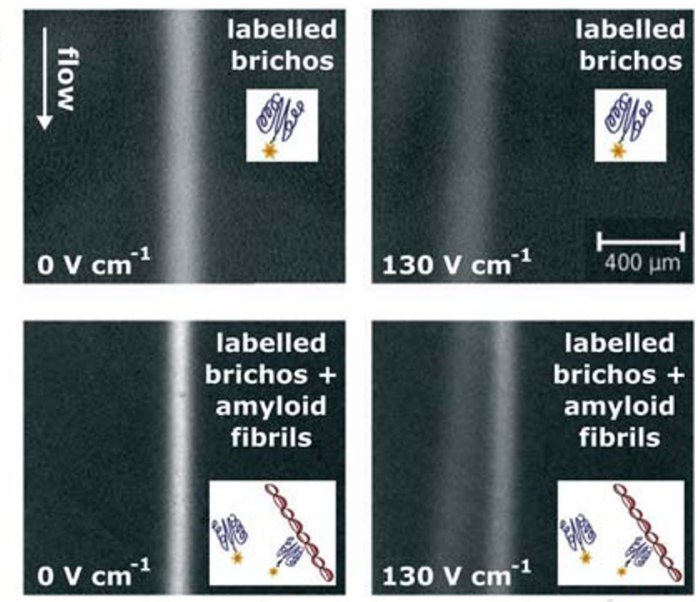

showing electrophoretic deflection of sample stream in $\mu \mathrm{FFE}$ (Herling et al. 2016). g Intensity profiles for electrophoretic deflection of fluorophore-labelled calmodulin $(\mathrm{CaM})$ in the absence and presence of creatine kinase-B (CKB) (Herling et al. 2016). $\mathbf{h}$ Quantitation by $\mu \mathrm{FFE}$ of dissociation constants between CaM and CKB in the presence and absence of $\mathrm{Ca}^{2+}$ (Herling et al. 2016). i $\mu$ FFE fractionation of Alexa488labelled pro-SPC brichos from fibrillar amyloid-beta (Saar et al. 2017). (Upper panels) Labelled brichos only, in the absence and presence of applied electric field perpendicular to flow (left and right panels, respectively). (Lower panels) Labelled brichos in the presence of amyloid fibrils, in the absence and presence of applied electric field perpendicular to flow (left and right panels, respectively)

experiments, aqueous sample solutions are partitioned into $\mathrm{fL}$ to $\mathrm{nL}$ droplets by a continuous oil phase and stabilised biophysical and biomedical analysis. In micro-droplet 
against coalescence by the presence of surfactant; each droplet represents a unique micro-reactor environment in which biochemical assays can be conducted. Droplets are commonly generated at frequencies of between 0.1 and $1 \mathrm{kHz}$, although rates of above $1 \mathrm{MHz}$ are feasible (Shim et al. 2013), and droplet compositions can be varied arbitrarily on a drop-todrop basis (Abate et al. 2010). Thus, droplet microfluidics enable rapid, high-throughput and massively parallel interrogation of biological systems. These properties, together with the fast mixing present in microdroplets (Chen et al. 2018), have been applied to the investigation of a variety of PPI systems. For example, rapid mixing and compartmentalisation, together with FRET microscopy, were used to study the binding kinetics between an antibody and angiogenin (ANG), a polypeptide implicated in angiogenesis and in tumour growth (Srisa-Art et al. 2009) (Fig. $3 \downarrow$ (a, b)). Analogously, rapid quantitation of the ANG-antibody binding interaction and that between chromatin-regulatory proteins and post-translationally modified histone peptides has been achieved via droplet microfluidics, combined with assay readout by fluorescence polarisation spectroscopy [Choi et al. 2012; Cheow et al. 2014).

When present at sufficiently low concentration, assay components can be encapsulated on a single-molecule or singleparticle basis (Collins et al. 2015; Mankowska et al. 2016). This enables the high-throughput study of phenomena relevant to PPIs on the single-molecule level, for example in the directed evolution of peptide binders against MDM2, a negative regulator of the tumour suppressor protein p53 (Iwakuma and Lozano 2003; Cui et al. 2016) (Fig. 3(c)). In this study, a library of DNA templates coding for a large variety (i.e. $10^{5}$ DNA sequences) of short peptide sequences were encapsulated on a single-molecule basis, before candidate peptide species were transcribed in-situ. Using a two-hybrid system (Zhou et al. 2014), the strength of peptide-binding to the coencapsulated MDM2 target was reported by fluorescence. Droplets displaying high fluorescence were then enriched by droplet sorting (Xi et al. 2017), and their DNA was sequenced to elucidate the identity of the highest affinity peptides for MDM2 binding (Fig. 3(d)).

The small volumes of microdroplets have been further exploited for the study of primary nucleation in protein aggregation. In bulk-phase studies, aggregation reactions are dominated by secondary effects that rapidly amplify the rate of protein misfolding (Knowles et al. 2009), which mask the observation of rare, stochastic primary nucleation events. In one study, the primary nucleation rate of insulin aggregation was quantitatively assessed by confinement of aggregation reactions in $\mathrm{pL}$ volumes, so that single nucleation events could be observed on a drop-by-drop basis, an approach that also enabled observation of the spatial and temporal propagation of insulin fibrillisation (Knowles et al. 2011) (Fig. 3(e, f)). Similarly, a study investigated ultrasensitive quantitation of preformed insulin aggregates, by employing single-particle encapsulation followed by target-driven signal amplification to observe the presence of amyloid propagons on a digital basis (Pfammatter et al. 2017), with a further work utilising intrinsic fluorescence to investigate proteinmisfolding events in microdroplets in a label-free manner (Toprakcioglu et al. 2019).

\section{Conclusion}

The continued investigation of PPIs and interaction networks are crucial tasks for an improved understanding of biological and pathological function. Microfluidic techniques present a facile route towards the analysis of PPIs in a native, label-free manner and on a timescale and in solution conditions relevant to their biological function, whilst requiring minimal sample consumption through the use of low-cost, miniaturised assays.

While a wide range of techniques presented here are in their infancy, even relatively well established methodologies such as MCE are yet to be readily adopted as the go-to technique for standard practice, where techniques such as MS and gel electrophoresis remain the laboratory workhorses. One issue preventing broader application of microfluidic approaches is that many fluidic methods are yet to be integrated into parallelised, high-throughput workflows as have become the norm in e.g. plate-reader assays via robotic automation. Indeed, assay parallelisation represents an essential criteria if microfluidic methods are to find success in the investigation of broader protein interaction networks, rather than being limited to the study of binary PPIs as is presently typical (Liu and Lu 2016). Although microfluidic platforms that enable highthroughput, parallel investigation of PPI networks have been demonstrated (Gerber et al. 2009), these approaches currently require surface-immobilisation of protein reagents. The integration of solution-phase microfluidic techniques, as discussed here, with parallelised, high-throughput assay workflows remains a critical challenge. Furthermore, current efforts to provide meaningful insight into PPIs using microfluidic techniques rely upon strong collaborative efforts in order to bring together the necessary expertise and facilities for both cutting-edge microfluidic studies, involving microfluidic engineering, fabrication and operation and relevant, high-quality experiments in the life sciences. Microfluidic tools themselves may present a means to address challenges regarding throughput and automation, as has been demonstrated by high-speed capillary electrophoresis (Floris et al. 2010; Pan et al. 2018) and the use of droplet microfluidics for rapid front-end sample processing (Ouimet et al. 2019), for example. Moreover, a variety of commercial microfluidic platforms relevant to the study of protein-protein 
a

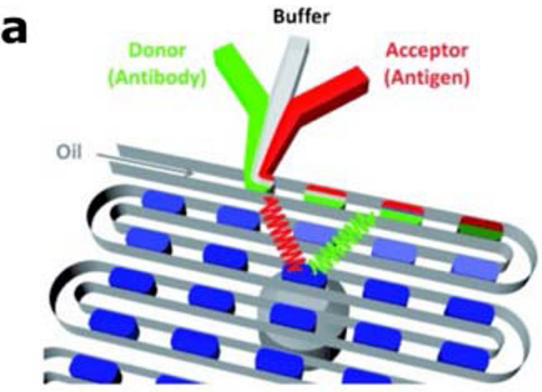

C

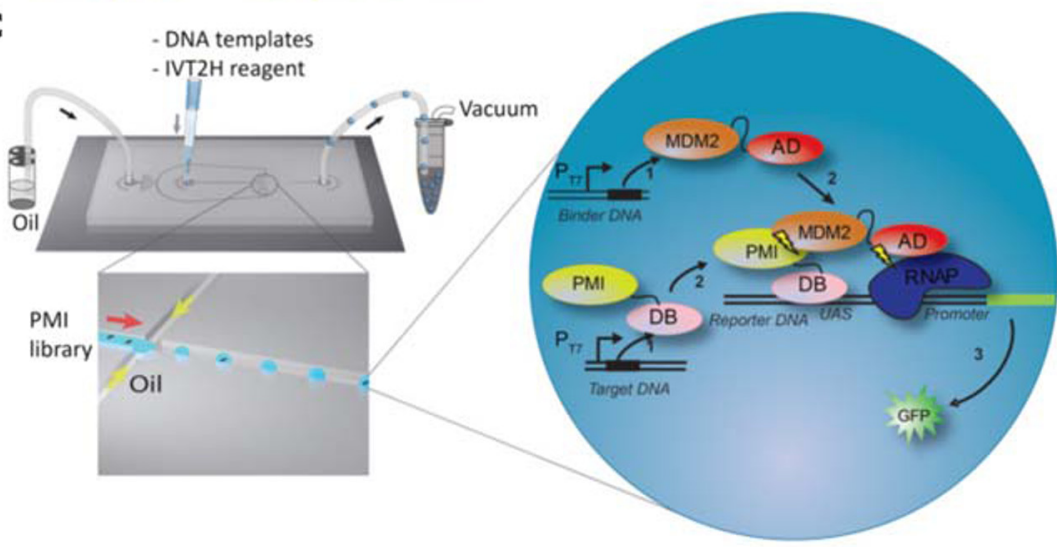

d
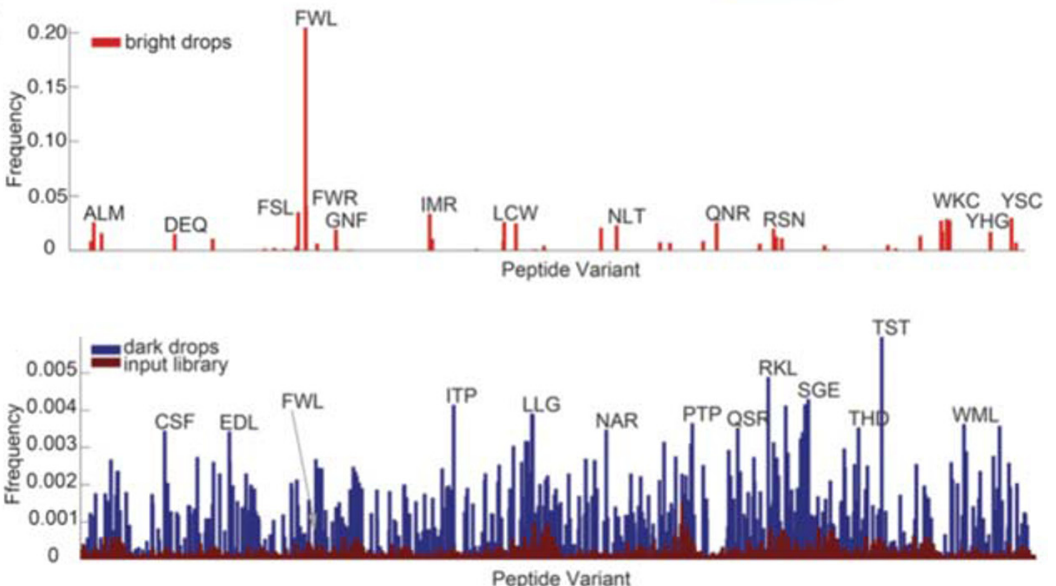

e

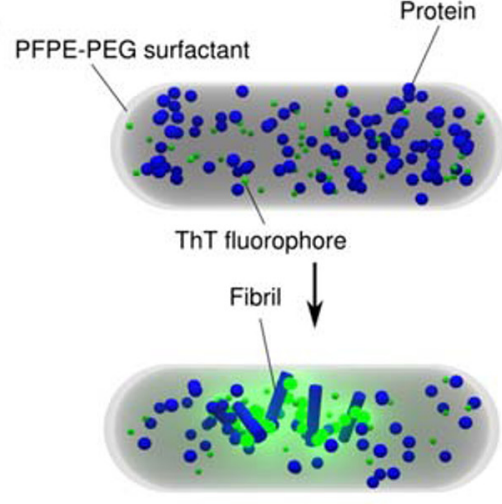

b

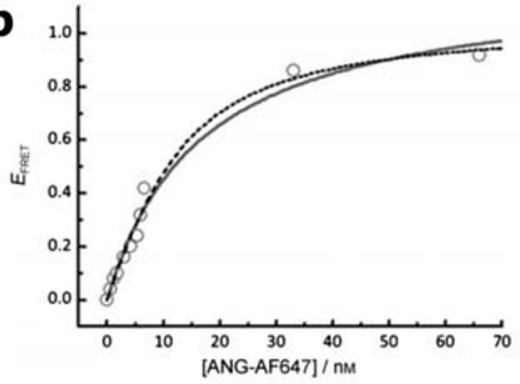


Fig. 3 Droplet-microfluidic methods for the investigation of PPI. aDroplet-based FRET experiment for the rapid characterisation of angiogenin-antibody binding interaction. b Determination of angiogenin-antibody dissociation constant by droplet-FRET. Figures taken with permission from (Srisa-Art et al. 2009). c Schematic for single-molecule transcription of short-peptide variants for enrichment of MDM2-binding peptides. d, (upper) Identities of high-binding peptides selected by droplet-enrichment relative to (lower) those transcribed from a random library. Figures taken with permission from (Cui et al. 2016). e Schematic showing principle for protein aggregation inside micro-droplet environments. f Brightfield (upper) and fluorescence (lower) micrographs showing initiation and propagation of insulin fibrillisation in a micro-droplet (Knowles et al. 2011).

illustrates, many studies have demonstrated the advantages of microfluidic techniques and their proof-of-concept application to the investigation of PPIs, presenting researchers in the field with the opportunity to adapt microfluidic approaches to their own systems of interest, so as to access parameter space and conduct experiments inaccessible with incumbent techniques.

Funding information We are grateful for financial support from the European Research Council under the European Union's Seventh Framework Programme (FP7/2007-2013) through the ERC grant PhysProt (agreement 337969) and from the Newman Foundation. The authors acknowledge support from the EPSRC Cambridge NanoDTC, EP/L015978/1 (W. E. A.), an Oppenheimer Early Career Fellowship (A. L) and the European Union's Horizon 2020 Framework Programme through the Marie Sklodowska-Curie grant MicroSPARK, agreement no. 841466 (G. K).

Open Access This article is licensed under a Creative Commons Attribution 4.0 International License, which permits use, sharing, adaptation, distribution and reproduction in any medium or format, as long as you give appropriate credit to the original author(s) and the source, provide a link to the Creative Commons licence, and indicate if changes were made. The images or other third party material in this article are included in the article's Creative Commons licence, unless indicated otherwise in a credit line to the material. If material is not included in the article's Creative Commons licence and your intended use is not permitted by statutory regulation or exceeds the permitted use, you will need to obtain permission directly from the copyright holder. To view a copy of this licence, visit http://creativecommons.org/licenses/by/4.0/.

\section{References}

Abate AR, Hung T, Marya P, Agresti JJ, Weitz DA (2010) Highthroughput injection with microfluidics using picoinjectors using picoinjectors. Proc Natl Acad Sci U S A 107(45):19163-19166

Arosio P, Müller T, Rajah L, Yates EV, Aprile FA, Zhang Y, Cohen SIA, White DA, Herling TW, De Genst EJ, Linse S, Vendruscolo M, Dobson CM, Knowles TPJ (2016) Microfluidic diffusion analysis of the sizes and interactions of proteins under native solution conditions. ACS Nano 10(1):333-341

Arter WE, Charmet J, Kong J, Saar KL, Herling TW, Müller T, Keyser UF, Knowles TPJ (2018) Combining affinity selection and specific ion mobility for microchip protein sensing. Anal Chem 90(17): 10302-10310

Bakail M, Ochsenbein F (2016) Targeting protein-protein interactions, a wide open field for drug design. C R Chim 19(1-2):19-27
Beebe DJ, Mensing GA, Walker GM (2002) Physics and applications of microfluidics in biology. Annu Rev Biomed Eng 4:261-286

Bork P, Jensen LJ, Von Mering C, Ramani AK, Lee I, Marcotte EM (2004) Protein interaction networks from yeast to human. Curr Opin Struct Biol 14(3):292-299

Bortolini C, Kartanas T, Copic D, Morales IC, Zhang Y, Challa PK, Peter Q, Jávorfi T, Hussain R, Dong M, Siligardi G, Knowles TPJ, Charmet J (2019) Resolving protein mixtures using microfluidic diffusional sizing combined with synchrotron radiation circular dichroism. Lab Chip 19(1):50-58

Challa PK, Peter Q, Wright MA, Zhang Y, Saar KL, Carozza JA, Benesch JLP, Knowles TPJ (2018) Real-time intrinsic fluorescence visualization and sizing of proteins and protein complexes in microfluidic devices. Anal Chem 90(6):3849-3855

Chamieh J, Leclercq L, Martin M, Slaoui S, Jensen H, Østergaard J, Cottet H (2017) Limits in size of Taylor dispersion analysis: representation of the different hydrodynamic regimes and application to the size-characterization of cubosomes. Anal Chem 89(24):1348713493

Chen C, Zhao Y, Wang J, Zhu P, Tian Y, Xu M, Wang L, Huang X (2018) Passive mixing inside microdroplets. Micromachines 9(4):160

Cheng S, Wu Z (2012) Microfluidic electronics. Lab Chip 12(16):27822791

Cheow LF, Viswanathan R, Chin C-S, Jennifer N, Jones RC, Guccione E, Quake SR, Burkholder WF (2014) Multiplexed analysis of proteinligand interactions by fluorescence anisotropy in a microfluidic platform. Anal Chem 86(19):9901-9908

Chiti F, Dobson CM (2017) Protein misfolding, amyloid formation, and human disease: a summary of progress over the last decade. Annu Rev Biochem 86(1):27-68

Chiu DT, Demello AJ, Di Carlo D, Doyle PS, Hansen C, Maceiczyk RM, Wootton RCR (2017) Small but perfectly formed? Successes, challenges, and opportunities for microfluidics in the chemical and biological sciences. Chem 2(2):201-223

Choi JW, Kang DK, Park H, Demello AJ, Chang SI (2012) Highthroughput analysis of protein-protein interactions in picolitervolume droplets using fluorescence polarization. Anal Chem 84(8):3849-3854

Collins DJ, Neild A, DeMello A, Liu A-Q, Ai Y (2015) The Poisson distribution and beyond: methods for microfluidic droplet production and single cell encapsulation. Lab Chip 15(17):3439-3459

Convery N, Gadegaard N (2019) 30 years of microfluidics. Micro Nano Eng 2:76-91

Cui N, Zhang H, Schneider N, Tao Y, Asahara H, Sun Z, Cai Y, Koehler SA, De Greef TFA, Abbaspourrad A, Weitz DA, Chong S (2016) A mix-and-read drop-based in vitro two-hybrid method for screening high-affinity peptide binders. Sci Rep 6:22575

Dobson CM (2003) Protein folding and misfolding. Nature 426(6968): 884-890

Duncombe TA, Tentori AM, Herr AE (2015) Microfluidics: reframing biological enquiry. Nat Rev Mol Cell Biol 16(9):554-567

Eichacker LA, Weber G, Sukop-Köppel U, Wildgruber R (2014) Free flow electrophoresis for separation of native membrane protein complexes. Methods Mol Biol 1295:415-425

Farcaș E, Pochet L, Crommen J, Servais AC, Fillet M (2017) Capillary electrophoresis in the context of drug discovery. J Pharm Biomed Anal 144:195-212

Figeys D, Aebersold R (1998) High sensitivity analysis of proteins and peptides by capillary electrophoresis-tandem mass spectrometry: recent developments in technology and applications. Electrophoresis 19(6):885-892

Floris A, Staal S, Lenk S, Staijen E, Kohlheyer D, Eijkel J, Van Den Berg A (2010) A prefilled, ready-to-use electrophoresis based lab-on-achip device for monitoring lithium in blood. Lab Chip 10(14):17991806 
Fonslow BR, Bowser MT (2005) Free-flow electrophoresis on an anodic bonded glass microchip. Anal Chem 77:5706-5710

Gambin Y, Vandelinder V, Ferreon ACM, Lemke EA, Groisman A, Deniz AA (2011) Visualizing a one-way protein encounter complex by ultrafast single-molecule mixing. Nat Methods 8(3):239-241

Garner AL, Janda KD (2011) Protein-protein interactions and cancer: targeting the central dogma. Curr Top Med Chem 11(3):258-280

Gerber D, Maerkl SJ, Quake SR (2009) An in vitro microfluidic approach to generating protein-interaction networks. Nat Methods 6(1):71-74

Goebel-Stengel M, Stengel A, Taché Y, Reeve JR (2011) The importance of using the optimal plasticware and glassware in studies involving peptides. Anal Biochem 414(1):38-46

Güven E, Duus K, Lydolph MC, Jørgensen CS, Laursen I, Houen G (2014) Non-specific binding in solid phase immunoassays for autoantibodies correlates with inflammation markers. J Immunol Methods 403:26-36

Hatch A, Kamholz AE, Hawkins KR, Munson MS, Schilling EA, Weigl BH, Yager P (2001) A rapid diffusion immunoassay in a T-sensor. Nat Biotechnol 19(5):461-465

Hawe A, Hulse WL, Jiskoot W, Forbes RT (2011) Taylor dispersion analysis compared to dynamic light scattering for the size analysis of therapeutic peptides and proteins and their aggregates. Pharm Res 28(9):2302-2310

Hellenkamp B, Thurn J, Stadlmeier M, Hugel T (2018) Kinetics of transient protein complexes determined via diffusion-independent microfluidic mixing and fluorescence stoichiometry. J Phys Chem B 122(49):11554-11560

Herling TW, Müller T, Rajah L, Skepper JN, Vendruscolo M, Knowles TPJ (2013) Integration and characterization of solid wall electrodes in microfluidic devices fabricated in a single photolithography step. Appl Phys Lett 102:184102

Herling TW, Arosio P, Müller T, Linse S, Knowles TPJ (2015) A microfluidic platform for quantitative measurements of effective protein charges and single ion binding in solution. Phys Chem Chem Phys 17(18):12161-12167

Herling TW, O'Connell DJ, Bauer MC, Persson J, Weininger U, Knowles TPJ, Linse S (2016) A microfluidic platform for real-time detection and quantification of protein-ligand interactions. Biophys J 110(9): 1957-1966

Horrocks MH, Li H, Shim J-u, Ranasinghe RT, Clarke RW, Huck WTS, Abell C, Klenerman D (2012) Single molecule fluorescence under conditions of fast flow. Anal Chem 84(1):179-185

Horrocks MH, Rajah L, Jönsson P, Kjaergaard M, Vendruscolo M, Knowles TPJ, Klenerman D (2013) Single-molecule measurements of transient biomolecular complexes through microfluidic dilution. Anal Chem 85(14):6855-6859

Huang CC, Cao Z, Chang HT, Tan W (2005) Protein-protein interaction studies based on molecular aptamers by affinity capillary electrophoresis. Anal Chem 76(23):6973-6981

Iljina M, Garcia GA, Horrocks MH, Tosatto L, Choi ML, Ganzinger KA, Abramov AY, Gandhi S, Wood NW, Cremades N, Dobson CM, Knowles TPJ, Klenerman D (2016) Kinetic model of the aggregation of alpha-synuclein provides insights into prion-like spreading. Proc Natl Acad Sci U S A 113(9):E1206-E1215

Iwakuma T, Lozano G (2003) MDM2, An introduction. Mol Cancer Res 1(14):993-1000

Justesen BH, Laursen T, Weber G, Fuglsang AT, Møller BL, Pomorski TG (2013) Isolation of monodisperse nanodisc-reconstituted membrane proteins using free flow electrophoresis. Anal Chem 85(7): $3497-3500$

Kamholz AE, Weigl BH, Finlayson BA, Yager P (1999) Quantitative analysis of molecular interaction in a microfluidic channel: the Tsensor. Anal Chem 71(23):5340-5347

Knowles TPJ, Waudby CA, Devlin GL, Cohen SIA, Aguzzi A, Vendruscolo M, Terentjev EM, Welland ME, Dobson CM (2009)
An analytical solution to the kinetics of breakable filament assembly. Science 326(5959):1533-1537

Knowles TPJ, White DA, Abate AR, Agresti JJ, Cohen SIA, Sperling RA, De Genst EJ, Dobson CM, Weitz DA (2011) Observation of spatial propagation of amyloid assembly from single nuclei. Proc Natl Acad Sci U S A 108(36):14746-14751

Krainer G, Broecker J, Vargas C, Fanghänel J, Keller S (2012) Quantifying high-affinity binding of hydrophobic ligands by isothermal titration calorimetry. Anal Chem 84(24):10715-10722

Krainer G, Keller S, Schlierf M (2019) Structural dynamics of membraneprotein folding from single-molecule FRET. Curr Opin Struct Biol 58:124-137

Kurmashev A, Kwon S, Park JK, Kang JH (2019) Vertically sheathing laminar flow-based immunoassay using simultaneous diffusiondriven immune reactions. RSC Adv 9(41):23791-23796

Lakowicz JR (2006) Principles of fluorescence microscopy. Springer

Lee CY, Wang WT, Liu CC, Fu LM (2016) Passive mixers in microfluidic systems: a review. Chem Eng J 288:146-160

Lin JS, Lai EM (2017) Protein-protein interactions: yeast two-hybrid system. Humana Press Inc.

Liu Y, Lu H (2016) Microfluidics in systems biology - hype or truly useful? Curr Opin Biotechnol 39:215-220

Liu Z, Gong Z, Dong X, Tang C (2016) Transient protein-protein interactions visualized by solution NMR. Biochim Biophys Acta, Proteins Proteomics 1864(1):115-122

Liu J, Zhao J, Li S, Zhang L, Huang Y, Zhao S (2017) A novel microchip electrophoresis-based chemiluminescence immunoassay for the detection of alpha-fetoprotein in human serum. Talanta 165:107-111

Macikova L, Sinica V, Kadkova A, Villette S, Ciaccafava A, Faherty J, Lecomte S, Alves ID, Vlachova V (2019) Putative interaction site for membrane phospholipids controls activation of TRPA1 channel at physiological membrane potentials. FEBS J 286(18):3664-3683

Mankowska SA, Gatti-Lafranconi P, Chodorge M, Sridharan S, Minter RR, Hollfelder F (2016) A Shorter Route to Antibody Binders via Quantitative in vitro Bead-Display Screening and Consensus Analysis. Scientific Reports 6(1)

Mazutis L, Baret JC, Treacy P, Skhiri Y, Araghi AF, Ryckelynck M, Taly V, Griffiths AD (2009) Multi-step microfluidic droplet processing: Kinetic analysis of an in vitro translated enzyme. Lab Chip 9(20): 2902-2908

Morris JH, Knudsen GM, Verschueren E, Johnson JR, Cimermancic P, Greninger AL, Pico AR (2014) Affinity purification-mass spectrometry and network analysis to understand protein-protein interactions. Nat Protoc 9(11):2539-2554

Mozafari M, El Deeb S, Krull F, Wildgruber R, Weber G, Reiter CG, Wätzig H (2018) Interaction of albumins and heparinoids investigated by affinity capillary electrophoresis and free flow electrophoresis. Electrophoresis 39(4):569-580

Ngounou Wetie AG, Sokolowska I, Woods AG, Roy U, Loo JA, Darie CC (2013) Investigation of stable and transient protein-protein interactions: Past, present, and future. Proteomics 13(3-4):538-557

Ngounou AG, Wetie IS, Woods AG, Roy U, Deinhardt K, Darie CC (2014) Protein-protein interactions: Switch from classical methods to proteomics and bioinformatics-based approaches. Cell Mol Life Sci 71(2):205-228

Olabi M, Stein M, Wätzig H (2018) Affinity capillary electrophoresis for studying interactions in life sciences. Academic Press Inc.

Ouimet CM, Shao H, Rauch JN, Dawod M, Nordhues B, Dickey CA, Gestwicki JE, Kennedy RT (2016) Protein cross-linking capillary electrophoresis for protein-protein interaction analysis. Anal Chem 88(16):8272-8278

Ouimet CM, D'amico CI, Kennedy RT (2017) Advances in capillary electrophoresis and the implications for drug discovery. Taylor and Francis Ltd.

Ouimet CM, D'Amico CI, Kennedy RT (2019) Droplet sample introduction to microchip gel and zone electrophoresis for rapid analysis of 
protein-protein complexes and enzymatic reactions. Anal Bioanal Chem 411(23):6155-6163

Pan JZ, Fang P, Fang XX, Hu TT, Fang J, Fang Q (2018) A low-cost palmtop high-speed capillary electrophoresis bioanalyzer with laser induced fluorescence detection. Sci Rep 8(1)

Park JK, Campos CDM, Neužil P, Abelmann L, Guijt RM, Manz A (2015) Direct coupling of a free-flow isotachophoresis (FFITP) device with electrospray ionization mass spectrometry (ESI-MS). Lab Chip 15(17):3495-3502

Pedde RD, Li H, Borchers CH, Akbari M (2017) Microfluidic-mass spectrometry interfaces for translational proteomics. Trends Biotechnol 35(10):954-970

Pedersen JT, Østergaard J, Houen G, Heegaard NHH (2008) Affinity capillary electrophoresis for identification and investigation of human Gc-globulin (vitamin D-binding protein) and its isoforms interacting with G-actin. Electrophoresis 29(8):1723-1733

Pfammatter M, Andreasen M, Meisl G, Taylor CG, Adamcik J, Bolisetty S, Sánchezsánchez-Ferrer A, Klenerman D, Dobson CM, Mezzenga R, Knowles TPJ, Aguzzi A, Hornemann S (2017) Absolute quantification of amyloid propagons by digital microfluidics. Anal Chem 89:12306-12313

Picou RA, Schrum DP, Ginger K, Cerqua RA, Indu K, Douglass Gilman $\mathrm{S}$ (2012) Separation and detection of individual $\mathrm{A} \beta$ aggregates by capillary electrophoresis with laser-induced fluorescence detection. Anal Biochem 425(2):104-112

Rauch JN, Nie J, Buchholz TJ, Gestwicki JE, Kennedy RT (2013) Development of a capillary electrophoresis platform for identifying inhibitors of protein-protein interactions. Anal Chem 85(20):9824 9831

Saar KL, Yates EV, Müller T, Saunier S, Dobson CM, Knowles TPJ (2016) Automated ex situ assays of amyloid formation on a microfluidic platform. Biophys J 110(3):555-560

Saar KL, Zhang Y, Muller T, Challa PK, Devenish S, Andrew L, Knowles TPJ (2017) On chip label free protein analysis with downstream electrodes for direct removal of electrolysis products. Lab Chip 18(1):162-170

Scheidt T, Łapińska U, Kumita JR, Whiten DR, Klenerman D, Wilson MR, Cohen SIA, Linse S, Vendruscolo M, Dobson CM, Knowles TPJ, Arosio P (2019) Secondary nucleation and elongation occur at different sites on Alzheimer's amyloid- $\beta$ aggregates. Sci Adv 5(4): eaau3112

Schuler B, Hofmann H (2013) Single-molecule spectroscopy of protein folding dynamics-expanding scope and timescales. Curr Opin Struct Biol 23(1):36-47

Shim JU, Ranasinghe RT, Smith CA, Ibrahim SM, Hollfelder F, Huck WTS, Klenerman D, Abell C (2013) Ultrarapid generation of femtoliter microfluidic droplets for single-molecule-counting immunoassays. ACS Nano 7(7):5955-5964

Song Y-A, Chan M, Celio C, Tannenbaum SR, Wishnok JS, Han J (2010) Free-flow zone electrophoresis of peptides and proteins in PDMS microchip for narrow $\mathrm{pI}$ range sample prefractionation coupled with mass spectrometry. Anal Chem 82(6):2317-2325

Squires TM, Quake SR (2005) Microfluidics: fluid physics at the nanoliter scale. Rev Mod Phys 77(3):977-1026

Srisa-Art M, Kang D-K, Hong J, Park H, Leatherbarrow RJ, Edel JB, Chang S-I, DeMello AJ (2009) Analysis of protein-protein interactions by using droplet-based microfluidics. ChemBioChem 10(10): 1605-1611

Sutandy FXR, Qian J, Chen CS, Zhu H (2013) Overview of protein microarrays. Curr Protoc Protein Sci 27

Tan DCW, Wijaya IPM, Andreasson-Ochsner M, Vasina EN, Nallani M, Hunziker W, Sinner EK (2012) A novel microfluidics-based method for probing weak protein-protein interactions. Lab Chip 12(15): 2726-2735

Toprakcioglu Z, Challa P, Xu C, Knowles TPJ (2019) Label-free analysis of protein aggregation and phase behavior. ACS Nano 13(23): 13940-13948

Turgeon RT, Bowser MT (2009) Micro free-flow electrophoresis: theory and applications. Anal Bioanal Chem 394(1):187-198

Turgeon RT, Fonslow BR, Jing M, Bowser MT (2010) Measuring aptamer equilbria using gradient micro free flow electrophoresis. Anal Chem 82(9):3636-3641

Velazquez-Campoy A, Leavitt SA, Freire E (2015) Characterization of protein-protein interactions by isothermal titration calorimetry. Springer, New York

Vergnon AL, Chu YH (1999) Electrophoretic methods for studying protein-protein interactions. Methods 19(2):270-277

Voeten RLC, Ventouri IK, Haselberg R, Somsen GW (2018) Capillary electrophoresis: trends and recent advances. Anal Chem 90(3): 1464-1481

Volpatti LR, Yetisen AK (2014) Commercialization of microfluidic devices. Trends Biotechnol 32:347-350

Wildgruber R, Weber G, Wise P, Grimm D, Bauer J (2014) Free-flow electrophoresis in proteome sample preparation. PROTEOMICS 14(4-5):629-636

Wittig L, Schägger H (2009) Native electrophoretic techniques to identify protein-protein interactions. Proteomics 9(23):5214-5223

Wright MA, Aprile FA, Bellaiche MMJ, Michaels TCT, Müller T, Arosio P, Vendruscolo M, Dobson CM, Knowles TPJ (2018) Cooperative assembly of Hsp70 subdomain clusters. Biochemistry 57(26):36413649

Wright MA, Ruggeri FS, Saar KL, Challa PK, Benesch JLP, Knowles TPJ (2019) Analysis of $\alpha \beta$-crystallin polydispersity in solution through native microfluidic electrophoresis. Analyst 144:44134424

Xi HD, Zheng H, Guo W, Gañán-Calvo AM, Ai Y, Tsao CW, Zhou J, Li W, Huang Y, Nguyen NT, Tan SH (2017) Active droplet sorting in microfluidics: a review. Lab Chip 17(5):751-771

Yates EV, Müller T, Rajah L, De Genst EJ, Arosio P, Linse S, Vendruscolo M, Dobson CM, Knowles TPJ (2015) Latent analysis of unmodified biomolecules and their complexes in solution with attomole detection sensitivity. Nat Chem 7(10):802-809

Zhang J, Yan S, Yuan D, Alici G, Nguyen N-T, Warkiani ME, Li W (2016a) Fundamentals and applications of inertial microfluidics: a review. Lab Chip 16:10-34

Zhang Y, Buell AK, Müller T, De Genst E, Benesch J, Dobson CM, Knowles TPJ (2016b) Protein aggregate-ligand binding assays based on microfluidic diffusional separation. ChemBioChem 17(20):1920-1924

Zhang Y, Yates EV, Hong L, Saar KL, Meisl G, Dobson CM, Knowles TPJ (2018) On-chip measurements of protein unfolding from direct observations of micron-scale diffusion. Chem Sci 9(14):3503-3507

Zhou Y, Asahara H, Schneider N, Dranchak P, Inglese J, Chong S (2014) Engineering bacterial transcription regulation to create a synthetic in vitro two-hybrid system for protein interaction assays. J Am Chem Soc 136(40): 14031-14038

Zijlstra N, Dingfelder F, Wunderlich B, Zosel F, Benke S, Nettels D, Schuler B (2017) Rapid microfluidic dilution for single-molecule spectroscopy of low-affinity biomolecular complexes. Angew Chem Int Ed 56(25):7126-7129

Publisher's note Springer Nature remains neutral with regard to jurisdictional claims in published maps and institutional affiliations. 